\title{
Performance Analysis and Simulation of Dual-Band PIFA Antenna for WCS applications
}

\author{
Mousumi Aktar ${ }^{1}$, Md. Bakul Hossain ${ }^{2}$ \\ Senior Lecturer, Dept. of EEE, Khwaja Yunus Ali University, Bangladesh ${ }^{1}$ \\ Student, Dept. of EEE, Khwaja Yunus Ali University, Bangladesh ${ }^{2}$
}

\begin{abstract}
This paper proposed a upturned T shape PIFA Antenna for wireless communication system (WCS) applications. This PIFA antenna is composed of ground plane, feeding post, shorting, plate patch antenna, connected to the ground plane.This desined antenna has been simulated by CST 2018 software. The proposed simulated antenna simulation results for the resonant frequency, return loss, radiation pattern and gain are presented and discussed. The performance analysis T shape PIFA antenna for various operating frequency are presented in this paper. . The proposed simulated antenna simulation results for the resonant frequency, return loss, radiation pattern and gain are presented and discussed. The performance analysis upturned T shape PIFA antenna for operating frequency of $2.368 \mathrm{GHz}$ and 6.677 $\mathrm{GHz}$ is presented in this paper. There a gain of $2.03 \mathrm{~dB}$ and $5.09 \mathrm{~dB}$ is obtained in lower and higher frequency respectively.
\end{abstract}

Keywords: PIFA, WCS, UPTURNED, HFSS

\section{INTRODUCTION}

Now days, the evolution of wireless communication devices has increased rapidly to fulfill the requirement of consumers. The performance of the wireless system is highly dependent on the design of antenna and its implementation. The technological advancement in the compact hand-hold wireless devices (ex:mobile phones) increases the demand of internal antennas. The PIFA antenna and Patch antenna are mass used internal antennas for the compact hand-held devices. The antennas must be small in size to construct into the device and have good performance in terms of bandwidth, return loss, gain etc. [1-2]. A patch antenna is a type of radio antenna with a low profile, which can be mounted on a flat surface. It consists of a planar rectangular, circular, triangular, or any geometrical sheet or "patch" of metal, mounted over a larger sheet of metal called a ground plane. They are the original type of microstrip antenna described by Howell in 1972.[7]A microstrip patch antenna (also known as a printed antenna) usually means an antenna fabricated using photolithographic techniques on a printed circuit board (PCB)[3]. Microstrip Patch antenna consists of a radiating patch built on the ground plane with the substrate of dielectric material sandwiched between them [4]. On the other hand, PIFA is similar to patch antenna but has a shorting element to decrease the physical length of antenna and has the radiating patch placed at some height from ground and substrate [5-6]. The antenna is usually connected to the transmitter or receiver through foil microstrip transmission lines. The radio frequency current is applied (or in receiving antennas the received signal is produced) between the antenna and ground plane. Microstrip antennas have become very popular in recent decades due to their thin planar profile which can be incorporated into the surfaces of consumer products, aircraft and missiles; their ease of fabrication using printed circuit techniques; the ease of integrating the antenna on the same board with the rest of the circuit. and the possibility of adding active devices such as microwave integrated circuits to the antenna itself to make active antennas [7-8]

\section{DESIGN CONSIDERATION FOR PATCH AND PIFA ANTENNA}

\section{A. Design Considerations for reference Patch Antenna}

The design steps for Patch antenna are illustrated with the help of flowchart as given in Fig. 1. First, the resonant frequency of antenna (fr), type of substrate and its dielectric constant (er) and height (h) is chosen and then the calculations of width, length and all the other dimensions for antenna has been prepared with the help of some standard equations as described in [10-11]

\section{B. Design Considerations for PIFA Antenna}

The proposed antenna has been designed and simulated using CST STUDIO 2018 Software. The listed elements in TABLE-2 have been used design the antenna. 


\section{DESIGN CONSIDERATION FOR PATCH AND PIFA ANTENNA}

Fig. 1 shows the structure for reference patch antenna

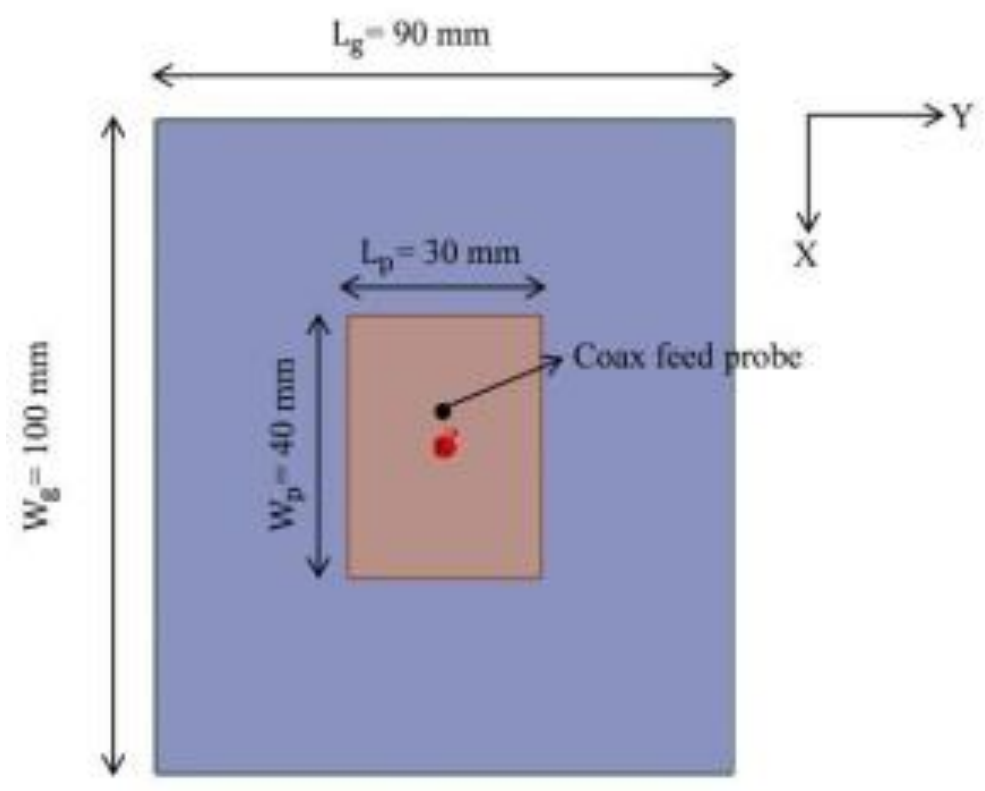

Fig.1: Structure of reference Patch Antenna in HFSS

TABLE 1 shows the detailed dimensions of proposed patch antenna structure. The structure consists of a rectangular patch of dimension $\mathrm{Lp} \times \mathrm{Wp}$, a substrate and ground plane of dimension $\mathrm{Lg} \times \mathrm{Wg}$. The substrate of material Rogers $\mathrm{RT} /$ duroid 5880 of dielectric constant $=2.2$ and height $=3.2 \mathrm{~mm}$ is used. The design steps mentioned in previous section were followed to obtain the dimensions for this structure and optimized for appropriate results.[1]

TABLE 1- DIMENSION FOR REFRENCE PATCH ANTENNA

\begin{tabular}{|l|l|}
\hline Dimension & Value $(\mathbf{m m})$ \\
\hline $\mathrm{Lg}$ & 100 \\
\hline $\mathrm{Wg}$ & 90 \\
\hline $\mathrm{Lp}$ & 40 \\
\hline $\mathrm{Wp}$ & 30 \\
\hline Substrate Material & Rogers RT/duroid 5880 \\
\hline Feed Type & Coaxial Probe \\
\hline $\begin{array}{l}\text { Length }=100 \mathrm{~mm} \\
\text { Height }=3.2 \mathrm{~mm}\end{array}$ & $\begin{array}{l}\text { Dielectric } \\
\text { constant }\left(\varepsilon_{\mathrm{r}}\right)=2.2\end{array}$ \\
\hline
\end{tabular}




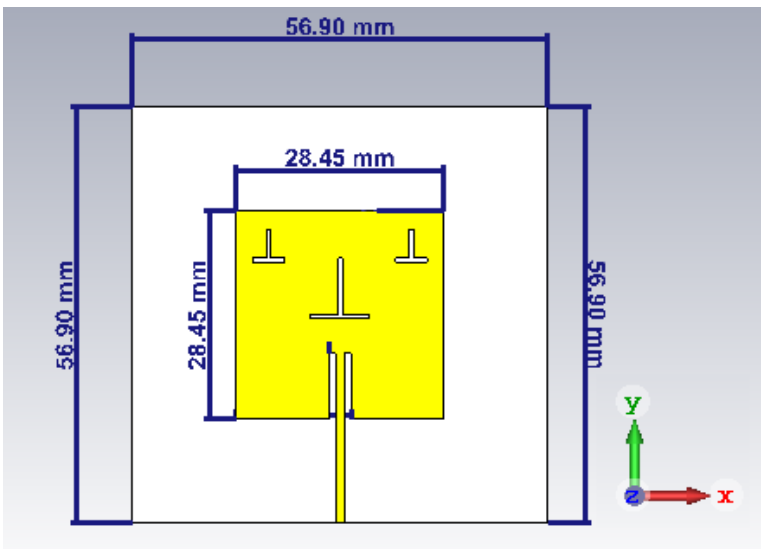

(a)

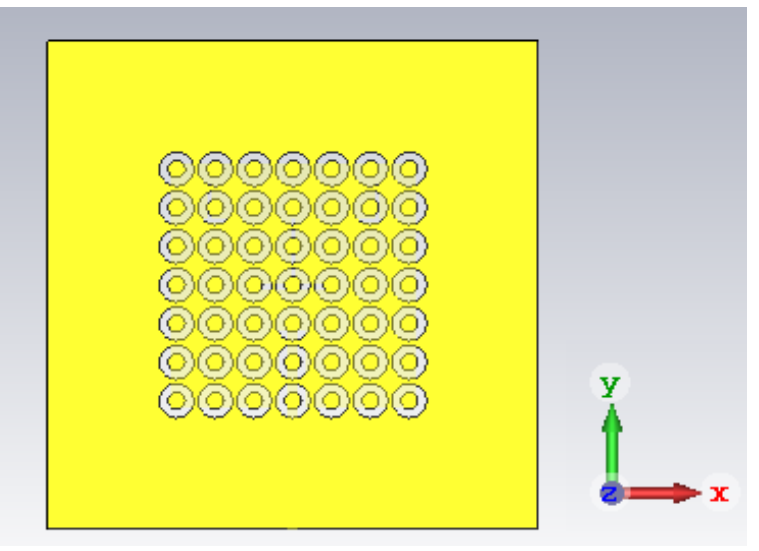

(b)

Fig.2: Structure of Proposed PIFA Antenna, (a) front view, (b) back view

TABLE 2- SPECIFICATIONS OF PROPOSED PIFA PARAMETERS

\begin{tabular}{|l|l|}
\hline Dimension & Value $(\mathrm{mm})$ \\
\hline $\mathrm{W}$ & 28.45 \\
\hline $\mathrm{L}$ & 28.45 \\
\hline $\mathrm{Wg}$ & $\mathrm{W}^{*} 2$ \\
\hline $\mathrm{Lg}$ & $\mathrm{L} * 2$ \\
\hline $\mathrm{ht}$ & 0.035 \\
\hline $\mathrm{hs}$ & 1.6 \\
\hline $\mathrm{Fi}$ & 9 \\
\hline $\mathrm{Gpf}$ & 1 \\
\hline Shape & Square \\
\hline Frequency of operation & $1-8 \mathrm{GHz}$ \\
\hline Dielectric Substance & FR-4(lossy) \\
\hline $\begin{array}{l}\text { Dielectric Constant of the } \\
\text { Substance }\left(\varepsilon_{\mathrm{r}}\right)\end{array}$ & 4.3 \\
\hline Feeding Method & Line feeding \\
\hline
\end{tabular}

\section{RESULT AND DISCUSSION}

A. Return Loss

The performance parameters of reference Patch Antenna have been simulated in Ansoft HFSS v.13 and PIFA Antenna have been simulated in CST Studio 2018. In Fig.3 and Fig.4 S11 parameters has been shown.

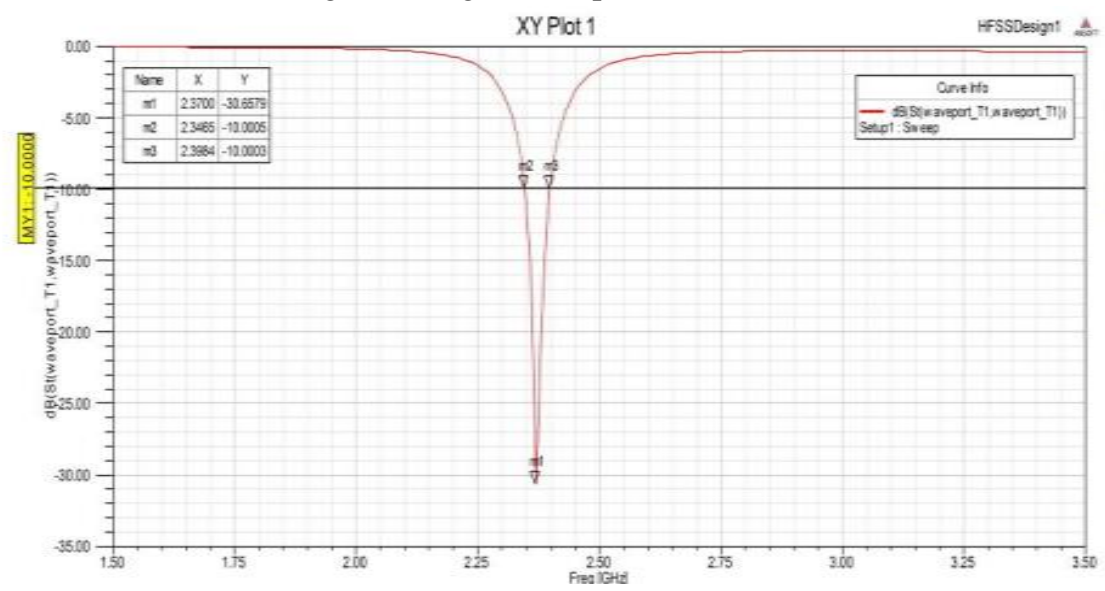

Fig.3: S11 Parameters of referenced Patch Antenna 


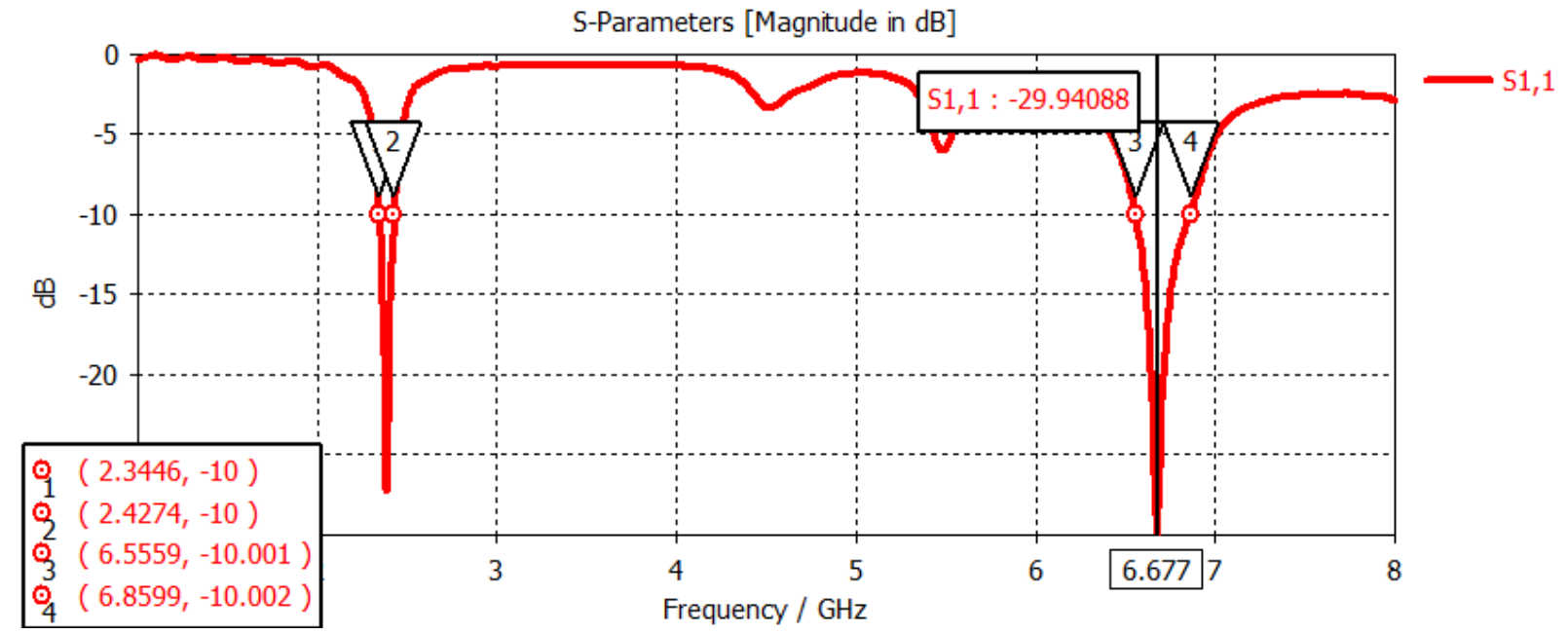

Fig.4: S11 Parameters of PIFA Antenna

The return loss in $\mathrm{dB}$ of reference Patch antenna is obtained $-30.6579 \mathrm{~dB}$ at the resonant frequency of $2.37 \mathrm{GHz}$, The impedance bandwith of the Patch antenna at $-10 \mathrm{~dB}$ return loss is $51.9 \mathrm{MHz}$. On other hand, the return loss db of proposed PIFA antenna is obtained dual band, bands are obtained $-27.3398 \mathrm{~dB}$ at the resonant frequency of $2.368 \mathrm{GHz}$ and -29.94088 $\mathrm{GHz}$ at the resonant frequency of $6.677 \mathrm{GHz}$. The impedance bandwith of PIFA antenna at $-10 \mathrm{~dB}$ returns loss is 82.8 $\mathrm{MHz}(2.3446-2.4274)$ and $304 \mathrm{MHz}(6.6559-6.8559)$ for resonant frequency of $2.368 \mathrm{GHz}$ and $6.677 \mathrm{GHz}$ respectively.

\section{B. VSWR (Voltage Stand Wave Ratio)}

The simulated results for VSWR of Patch antenna are shown in Fig.5. The value of VSWR for Patch antenna at resonant frequency of $2.37 \mathrm{GHz}$ is obtained as 0.5094 .

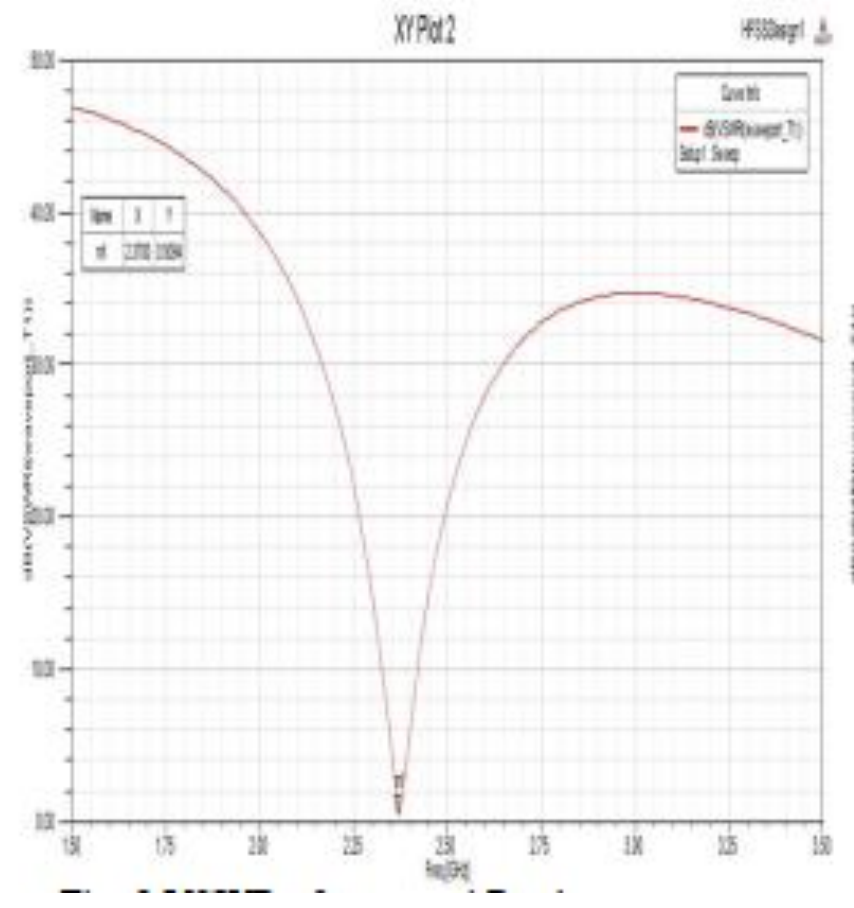

Fig.5: VSWR of reference Patch antenna 


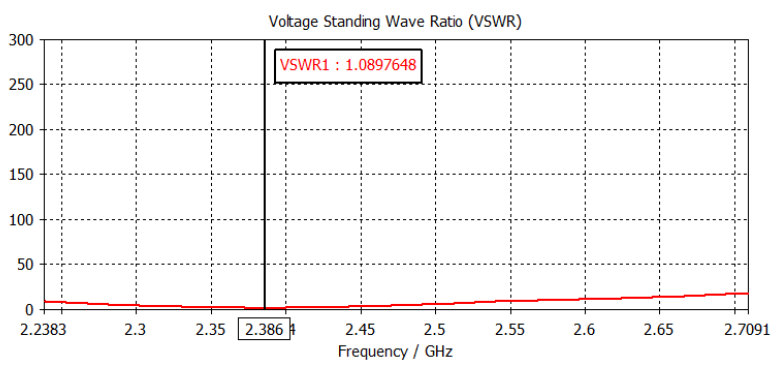

(a)

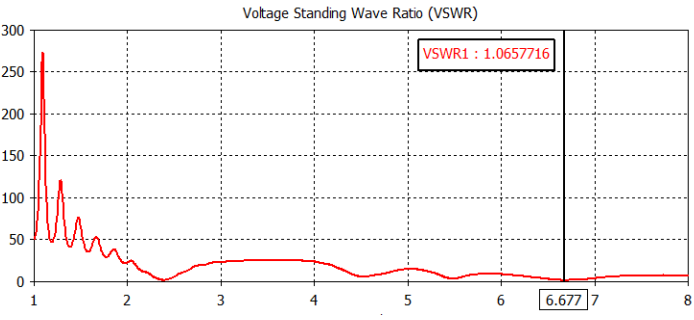

(b)

Fig.5: VSWR of proposed PIFA antenna;

(a) at resonance frequency of $2.386 \mathrm{GHz}$

(b) at resonance frequency of $2.386 \mathrm{GHz}$

On other hand, the simulated results for VSWR of proposed PIFA antenna are shown in Fig.6 .The VSWR for proposed PIFA antenna are 1.0897648 at resonance frequency of $2.386 \mathrm{GHz}$ and 1.065716 at resonance frequency of $6.677 \mathrm{GHz}$.

\section{COMPARISON RESULS}

\begin{tabular}{|c|c|c|c|}
\hline S.L NO & Parameters & Reference antenna & Proposed PIFA antenna \\
\hline 1 & Resonant Frequency (f) & $2.4 \mathrm{GHz}$ & $\begin{array}{c}2.368 \mathrm{GHz} \text { at }-27.33 \mathrm{~dB} \\
\text { and } 6.677 \mathrm{GHz} \text { at }-29.94 \mathrm{~dB}\end{array}$ \\
\hline 2 & Bandwith $(-10 \mathrm{~dB})$ & $51.9 \mathrm{MHz}$ & $82.8 \mathrm{MHz}$ and $304 \mathrm{MHz}$ \\
\hline 3 & Return Loss & $-30.6579 \mathrm{~dB}$ & $-27.3398 \mathrm{~dB}$ and \\
& & & $-29.9408 \mathrm{~dB}$ \\
\hline 4 & VSWR & 0.5094 & 1.0897 and 1.065716 \\
\hline
\end{tabular}

\section{CONCLUSION}

In this paper, the reference Patch antenna is a single band coax-fed rectangular Patch antenna, which operating frequency is $2.4 \mathrm{GHz}$. The performance parameters of reference Patch Antenna have been simulated in Ansoft HFSS v.13 and PIFA Antenna have been simulated in CST Studio 2018. The return loss in dB of reference Patch antenna is obtained -30.6579 $\mathrm{dB}$ at the resonant frequency of $2.37 \mathrm{GHz}$, The impedance bandwith of the Patch antenna at -10dB return loss is $51.9 \mathrm{MHz}$. On other hand, the return loss db of proposed PIFA antenna is obtained dual band, bands are obtained $-27.3398 \mathrm{~dB}$ at the resonant frequency of $2.368 \mathrm{GHz}$ and $-29.94088 \mathrm{GHz}$ at the resonant frequency of $6.677 \mathrm{GHz}$. The impedance bandwith of PIFA antenna at $-10 \mathrm{~dB}$ returns loss is $82.8 \mathrm{MHz}(2.3446-2.4274)$ and $304 \mathrm{MHz}(6.6559-6.8559)$ for resonant frequency of $2.368 \mathrm{GHz}$ and $6.677 \mathrm{GHz}$ respectively. The value of VSWR for Patch antenna at resonant frequency of $2.37 \mathrm{GHz}$ is obtained as 0.5094. And the simulated results for VSWR of proposed PIFA antenna are shown in Fig.6 .The VSWR for proposed PIFA antenna are 1.0897648 at resonance frequency of $2.386 \mathrm{GHz}$ and 1.065716 at resonance frequency of 6.677 $\mathrm{GHz}$. The comparison of Patch and PIFA antenna in terms of return loss was also obtained. From the results, it is revealed that PIFA antenna shows better than Patch antenna.

\section{REFERENCES}

[1] Amrit Kaur, Anjali, "Performance Analysis of Patch and PIFA Antenna for WCS and SDR Applications" International Journal of Advanced Research in Computer and Communication Engineering,Vol. 6, Issue 7, pp.265, July 2017.

[2] Ankur Kaushal, "Microstrip patch antenna, its types, merits demerits and its applications", International Journal of Engineering Sciences and Research Technology, Vol. 4, Issue 7, pp. 619-622, July 2015.

[3] Lee, Kai Fong; Luk, Kwai Man (2017). Microstrip Patch Antennas. World Scientific. pp. 8-12. ISBN 978-9813208612.

[4] B.Sai Sandeep, "Design and simulation of microstrip patch array antenna for wireless communications at 2.4 GHz", International Journal of Scientific and Engineering Research, Vol. 3, Issue 11, pp. 1-5, November 2012. 
International Journal of Advanced Research in Computer and Communication Engineering

Vol. 10, Issue 3, March 2021

\section{DOI 10.17148/IJARCCE.2021.10301}

[5] Online]Available:http://www.antenna-theory.com/antennas/patches/pifa.php. [Accessed: 10-Nov-2016]M.Young, The Technical Writer's Handbook. Mill Valley, CA: University Science, 1989.

[6] Ashutosh Joshi, "Design and simulation of Planar Inverted F Antenna for ISM band applications using HFSS", International Journal of Scientific and Engineering Research, Vol. 5, Issue 4, pp. 1114-1118, April 2014.

[7] [Online]Availabe:https://en.wikipedia.org/wiki/Microstrip_antenna

[8] [Online]Available:https://www.antenna-theory.com/antennas/aperture/ifa.php

[9] K.R.Boyle and P. G.Steeneken," A Five-Band Reconfigurable PIFA for Mobile Phones", IEEE Trans.Antennas and Propagat., Vol. 55, No. 11, Nov. 2007.

[10] Constantine A. Balanis, Antenna Theory Analysis and Design, John Wiley and Sons, Inc., Second edition, 1997.

[11] Ansoft HFSS-User Guide, ANSYS, Inc., 3rd Edition, February 20, 2009. 